\title{
GEOCODING LOCATIONS OF HISTORIC RECLAMATION RESEARCH SITES USING GOOGLE EARTH ${ }^{1}$
}

\author{
Ruopu $\mathrm{Li}^{2}$ and Kaitlyn Holtsclaw
}

\begin{abstract}
The American Society of Mining and Reclamation (ASMR) has been publishing conference proceedings and journal articles on land reclamation and the protection of soil and water resources for more than three decades. Much of the technical work presented in the ASMR conferences and journals contain specific mining sites that are associated with geographic locations. However, the geographic contexts of these articles were often not made directly available to the readers. This deficiency affects the abilities of related professionals to explore the technical reclamation knowledge in terms of its geographic background. Therefore, it is critical to develop quality-assured geographic references to the papers published by ASMR. This study used Google Earth and ArcGIS software to create a series of placemarks that link past ASMR technical articles to the actual locations. These placemarks can be freely distributed and integrated into the website for web map display.
\end{abstract}

Key Words: ASMR, geocoding, ArcGIS, placemark, and Google Earth

\footnotetext{
${ }^{1}$ Paper submitted to JASMR for work done for the ASMR in geocoding locations of historic reclamation research sites that had been presented separately to the ASMR between 1988 and 1997.

${ }^{2}$ Ruopu Li, Ph.D., Assistant Professor, Department of Geography \& Environmental Resources Southern Illinois University-Carbondale, IL 62901; and Kaitlyn Holtsclaw, Department of Plant Biology, Southern Illinois University- Carbondale, IL 62901.
}

Journal American Society of Mining and Reclamation, 2017 Volume 6, Issue 2 pp 84-92

DOI: http://doi.org/10.21000/JASMR17020084 


\section{Introduction}

The American Society of Mining and Reclamation (ASMR) has been publishing annual conference proceedings and journal articles on land reclamation and conservation of soil and water resources for over three decades. Much of the technical work presented at ASMR conferences and in the ASMR Journal has rich geographic contextual information on specific mining sites or locations. However, these locations were often not directly available or geotagged in a userfriendly format. This situation affects the abilities of ASMR members and other mining and reclamation professionals to explore the technical knowledge in terms of the publication's geographic contexts. Therefore, it is critical to develop a new dataset that can relate the technical papers to the actual landscape using modern geospatial tools.

Previously, projects have been conducted to relate the texts and multimedia contents to actual geographic locations through geotagging (e.g., Hunter, 2012; Rupp et al., 2014). Google Earth ${ }^{\mathrm{TM}}$ has been a geospatial platform with particular popularity due to its ease of use, free availability, and high-resolution earth observation images. Google Earth allows the world community to communicate data and research findings in an intuitive 3D global perspective (Yu and Gong, 2011). The placemarks, i.e., spatial tags used by Google Earth, can be created to link past ASMR technical papers or journal articles to the actual locations on the earth surface. These placemarks can be freely distributed and integrated into the ASMR website for web map display. The objective of this project is to provide quality-assured geographic references to proceeding papers from the ASMR conferences held during 1988-1997.

\section{Methods}

ESRI ArcGIS 10.2 (ESRI, 2011) and Google Earth were employed to develop the placemarks to geocode the conference proceeding papers. A total of 5 undergraduate and 2 graduate students from the SIU GIS Club, a registered student organization at Southern Illinois UniversityCarbondale (SIUC), were dedicated to the interpretation of the locational information contained in each paper using Google Earth (Map data: Google, Digital Globe). The flowchart of the general work flow is shown in Fig. 1. 


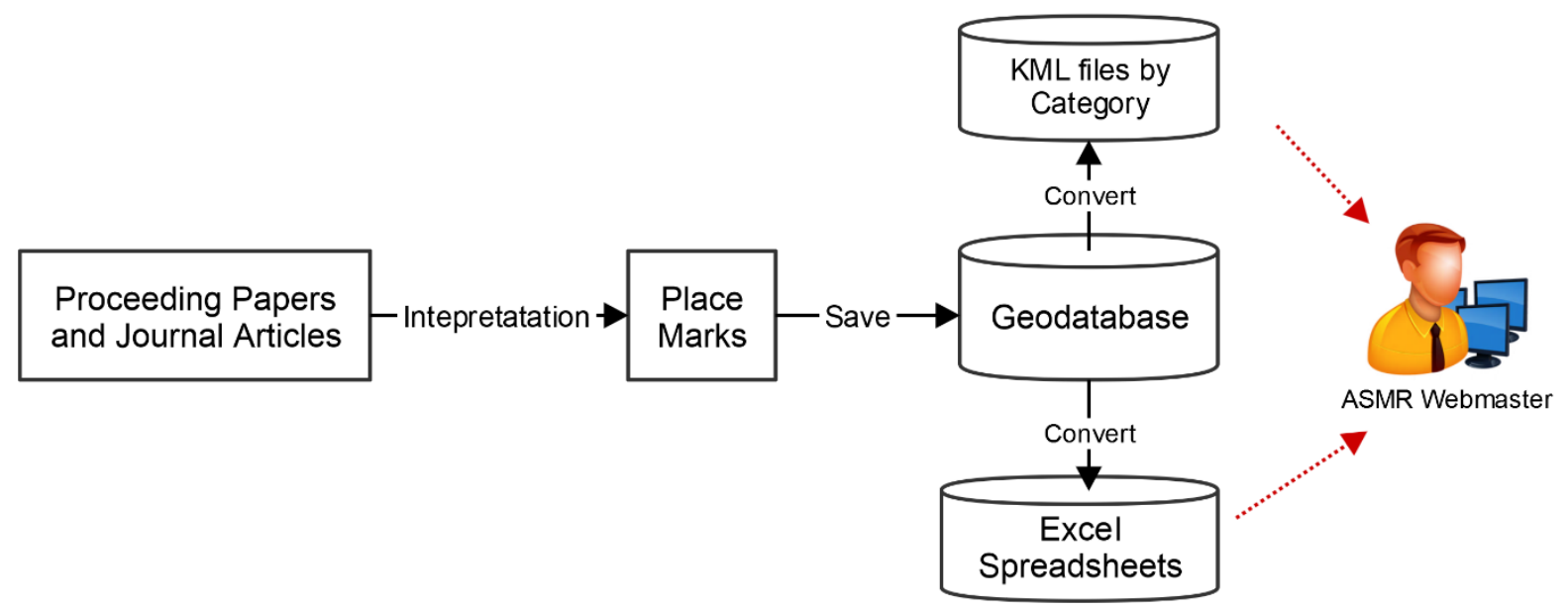

Figure 1. A flowchart of the work flow to complete the project.

To begin the project, students read through titles, abstracts, keywords, and full texts, if available, of each paper included in ASMR conference proceedings published during 1988-1997 to identify key locational information, such as the names of towns, forests, and zip codes. Then, the site locations associated with the proceeding papers were cross-referenced in the rich geospatial context provided by the Google Earth software. It is noted that some conference proceedings contained reference to more than one site. For example, Hart (1989) had nine placemarks for a single paper due to multiple sites. The papers without discernible location information, e.g., those focusing only on lab procedures, were excluded from the geocoding. A corresponding placemark was created for each location accordingly. Place-mark information typed into the Google Earth included key attributes associated with the location recorded in the 'Description' field of the placemarks, including the publication year, authors, article titles, and technical divisions that were delimited by semicolons (Fig. 2). The place marks were then saved as a KML (a.k.a., Keyhole Markup Language) or KMZ (i.e., zipped KML) files. 


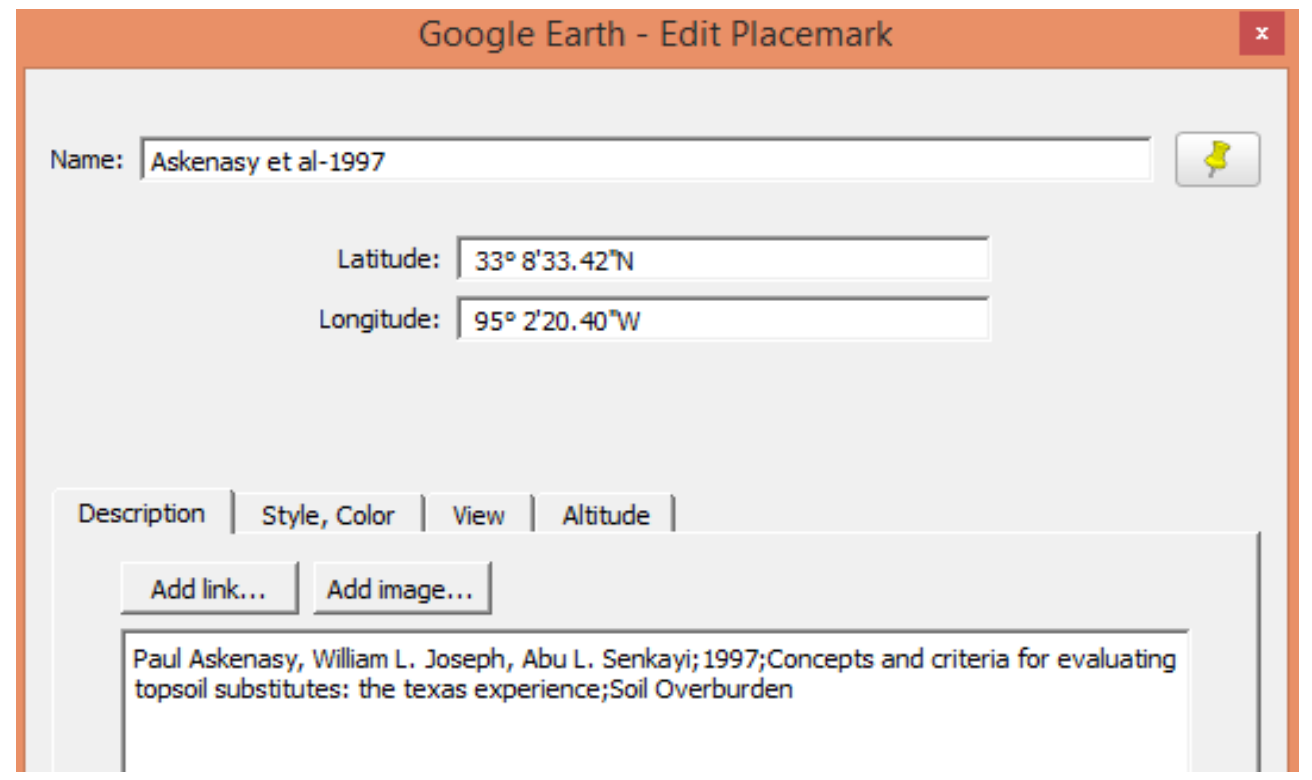

Figure 2. An example of the publication information recorded and its format for creating a placemark.

Once the KML/KMZ file was completed, the ArcGIS Desktop software was to used convert the file to a feature class in a single geodatabase. Multiple KML/KMZ files created by different persons were merged in this geodatabase. The attribute information was available in a field "PopupInfo," which corresponds to the information recorded in the 'Description' field of the placemarks. At this step, the semicolon-delimited information was parsed as 4 independent fields (i.e., authors, publication years, paper titles, and technical divisions) using the ArcGIS Field Calculator (Fig. 3). The technical division attribute was used to represent the general, technical or research subject areas, which include: Ecology, Forestry and Wildlife, Geotechnical Engineering, International Tailings Reclamation, Landuse Planning and Design, Soil Overburden, and Water Management, which was sub-divided into Mine Water Treatment, Water Hydrology. In addition, Education and Other placemarks were used for locations that did not fall into one of the seven Technical Divisions of ASMR.

Data quality is critical to achieving the project objectives. Quality Assurance and Quality Check (QAQC) procedures focused on positional accuracy, attribute accuracy, logical consistency, and data completeness and was conducted in the following three steps. Student workers first checked for typos, positional correctness, formatting consistency and other technical issues before the initial submission of the placemark files. Second, the project manager's graduate assistant inspected the quality of the product and provided detailed feedbacks and guidance for quality 
improvement. Lastly, the project manager checked the entire dataset and fixed other problems identified in the data analysis and reporting.

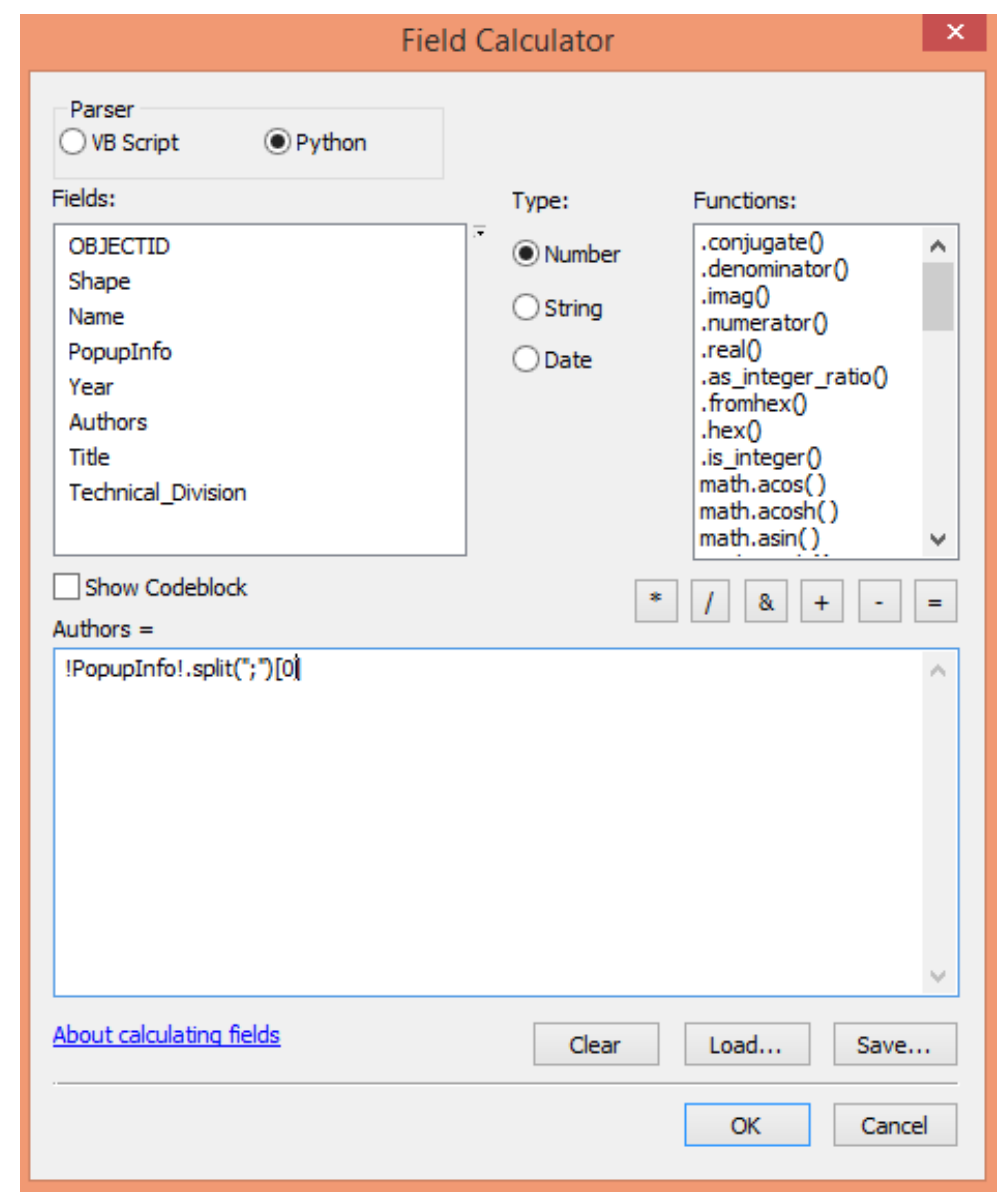

Figure 3. The ArcGIS Field Calculator is information is delimited using a semi-colon to parse the data into new fields.

After the QAQC, the geodatabase was reorganized into subsets of data based on the publication years and technical divisions of the conference proceedings. These subsets were further exported into new KMZ files using the 'Make Feature Layer' and 'Layer to KML' tools available in ArcGIS. The final placemark dataset was also exported into a dBase tables, which were then reformatted as a Microsoft Excel 2010 spreadsheet file. Both KMZ files and Excel tables were important deliverables for the ASMR.

\section{$\underline{\text { Results and Discussion }}$}

We developed 766 placemark locations distributed in countries across the world (Fig. 4), most of which, $91.4 \%$, are located in North America (U.S. and Canada). Overall, the U.S. (634), Canada 
(66), and Australia (19) are the top three countries with the largest number of conference proceedings that can be referenced to geospatial locations. Within the United States, the documented sites with locational information predominately concentrate along the Rocky Mountains and Appalachian Mountains, where the most intensive mining activities existed historically (Fig. 5).

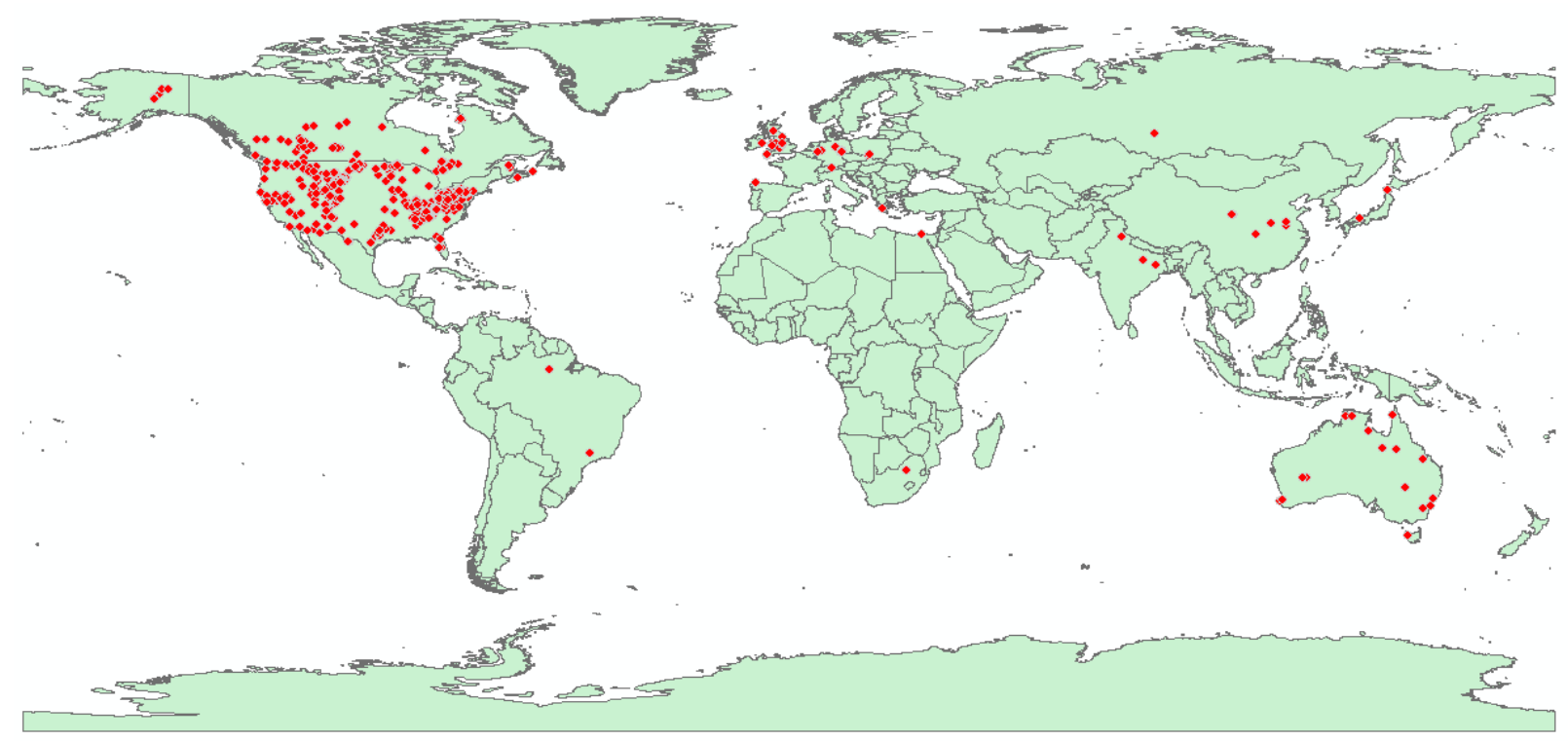

Figure 4. Spatial distribution of the placemarks across the world that were documented in ASMR Conference Proceedings between 1988 and1997.

This project provided two versions of Google Earth placemarks based on the publication years and the technical divisions of the conference proceedings (Fig. 6) and a Microsoft Excel file. The icons of pushpins were used to label and distinguish different types of placemarks. The format of the placemarks was available as both KML and KMZ files. The KMZ file was selected for use because the mini pictures of pushpin icons can be stored in one KMZ file and the size of a KMZ file is also smaller than a KML one. In the Excel file, the latitude and longitude of each location were provided.

Geographic conditions are important constraints of the reclamation success of abandoned mining sites (Sengupta, 1993; Pallavicini et al., 2015). Google Earth placemarks, when loaded in the software, are able to provide such important geographic context information for the related research and demonstration papers. The results may be compared with and used to complement the Abandoned Mine Land Inventory System (e-AMLIS) managed by the Office of Surface Mining and Reclamation. The e-AMLIS is a computer system that stores, manages, and reports 
problems that are in need of reclamation or those mines that have been reclaimed (e-AMLIS, 2017). It is noted that there could be multiple means of achieving the same results, such as using Microsoft Excel to document the locational information and converting it to placemarks. For the future work, a pilot study of using Optical Character Recognition (OCR) and machine learning techniques will be conducted to produce the placemarks in a semi-automatic or automatic manner.

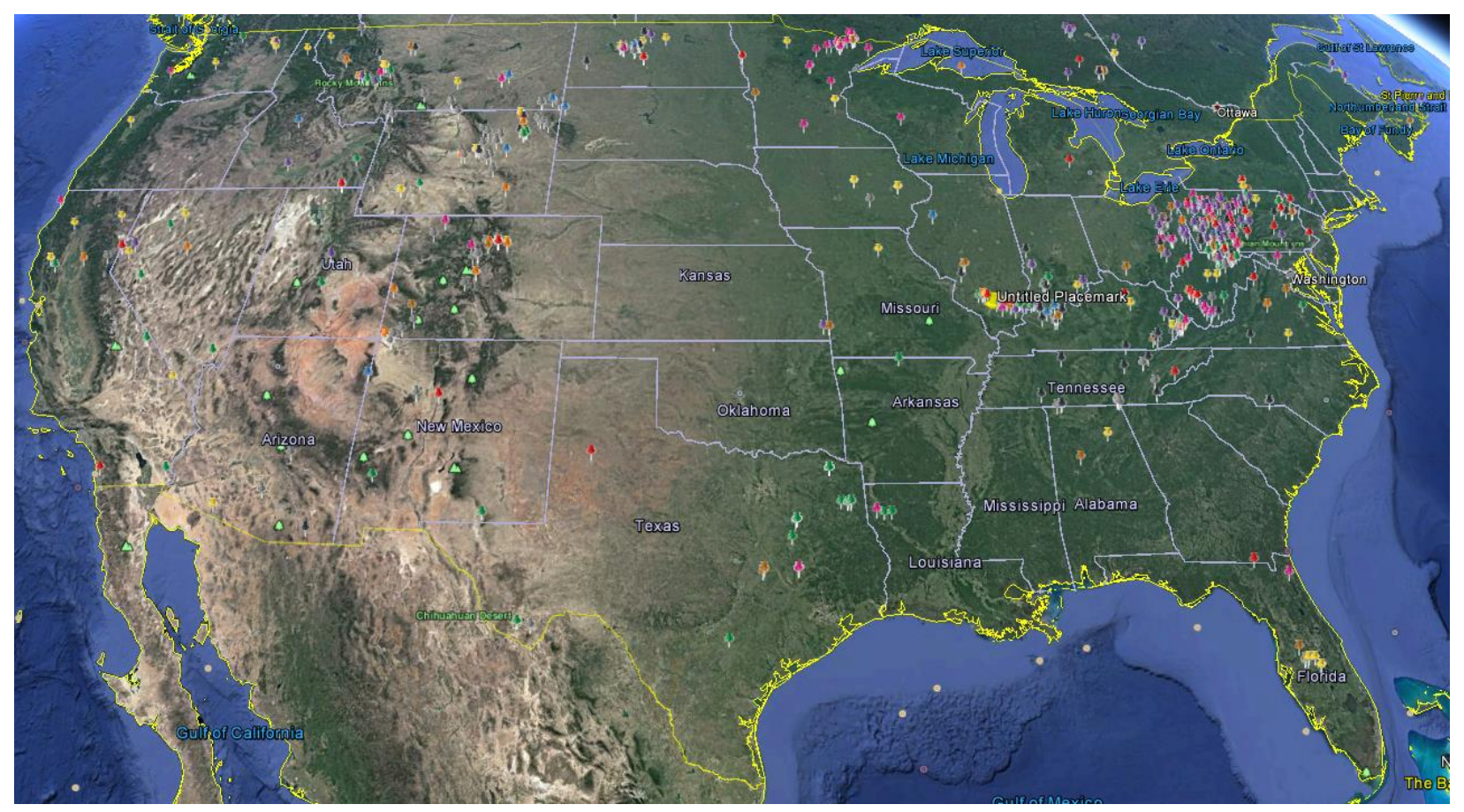

Figure 5. Distribution of the place-marks in the Google Earth map within the spatial extent of the United States.
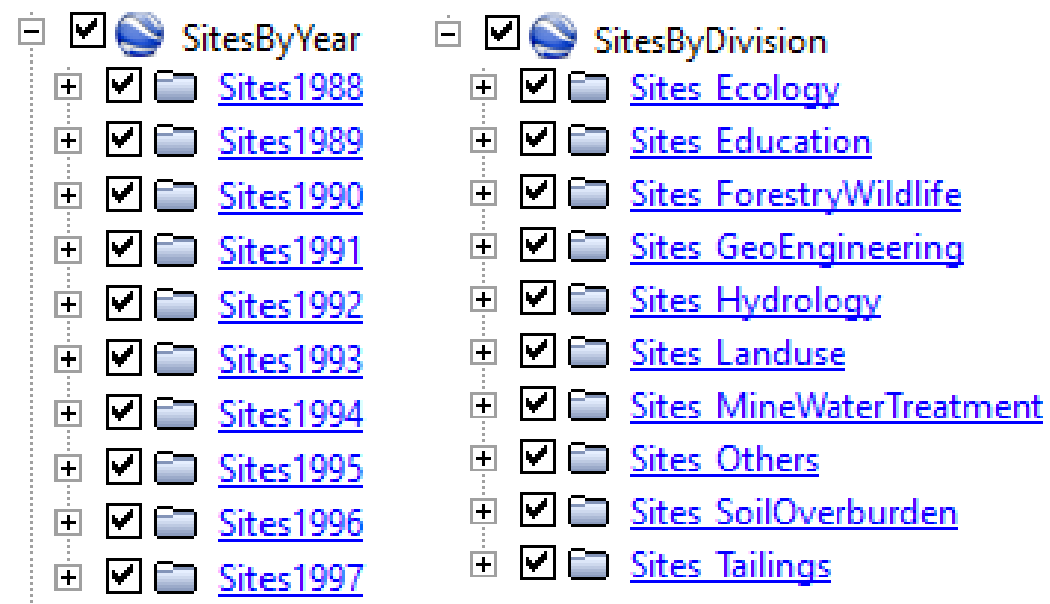

Figure 6. The Google Earth placemarks grouped based on the publication year and technical division. 


\section{Summary}

This project demonstrates a method and the results of using Google Earth and ArcGIS to geocode the location of research projects published in historic ASMR conference proceeding papers on mining and reclamation. The data production process was carefully inspected based on a systematic QAQC approach. A total of 766 placemarks distributed across the world were produced and organized as subsets based on publication year and technical division. These placemarks can be freely distributed and integrated into the website for web map display.

\section{Acknowledgments}

We are grateful to ASMR for their generous funding and technical support for this project. We would like to express sincere thanks to the following students for their hard work on researching and locating the placemarks: Tarig Mohamed and Brandon Polk (graduate students), Anastasia Maranto, Jatoya Hale, and Elizabeth Wilson (undergraduate students).

\section{$\underline{\text { References }}$}

Abandoned Mine Land Inventory System (e-AMLIS). 2017. Abandoned Mine Land Inventory System (e-AMLIS). [accessed 2017 Jul 11]. http://www.osmre.gov/programs/AMLIS.shtm

ESRI 2011. ArcGIS Desktop: Release 10. Redlands, CA: Environmental Systems Research Institute.

Hart, R.T., 1989. Salt tailings - The ultimate saline reclamation challenge. Proceedings American Society of Mining and Reclamation: 543-554. [accessed 2017 Jul 11]. http://www.asmr.us/Portals/0/Documents/Conference-Proceedings/1989/0543-Hart.pdf

Hunter, D.S. 2012. eBook Geotagging: Linking Literature and Location. Volume 14, Papers in Resource Analysis. 14 pp. Saint Mary’s University of Minnesota University Central Services Press. Winona, MN. Retrieved (June 3, 2017) http://www.gis.smumn.edu

Pallavicini, Y., J.G. Alday, and C. Martínez-Ruiz, 2015. Factors affecting herbaceous richness and biomass accumulation patterns of reclaimed coal mines. Land Degradation \& Development, 26: 211-217. https://doi.org/10.1002/ldr.2198 
Rupp, C.J., P. Rayson, I. Gregory, A. Hardie, A. Joulain, D. Hartmann. 2014. Dealing with heterogeneous big data when geoparsing historical corpora, Big Data (Big Data) 2014 IEEE International Conference on, pp. 80-83. DOI: 10.1109/BigData.2014.7004457

Sengupta M., 1993. Environmental impacts of mining: monitoring, restoration, and control. Lewis Publishers: Boca Raton, FL.

Yu, L. and P. Gong, 2012. Google Earth as a virtual globe tool for Earth science applications at the global scale: progress and perspectives. International Journal of Remote Sensing 33, 39663986. http://doi.org/doi:10.1080/01431161.2011.636081 